\title{
Performance Evaluation of Lighting Fixtures and Installations for Renewable Energy Applications
}

\author{
Oriola Akinradewo $^{1} \quad$ Obiseye Obiyemi $^{1} \quad$ Oyelami Seun $^{2}$ \\ 1.Department of Electrical and Electronics Engineering, Osun State University, Osogbo, Nigeria \\ 2.Department of Mechanical Engineering, Osun State University, Osogbo, Nigeria
}

\begin{abstract}
Energy efficiency has been viewed as the most accessible and cost effective form of alternative energy. While lighting occupies only a percentage in the total electric loads in homes, technological advances in Light Emitting Diodes (LED) are becoming more convincing in their power consumption and lumens output. This paper evaluates the percentage lighting occupied in the total load spectrum on the two main buildings in Osun State University, verifies the light level in the library reading rooms (a place where adequate lighting is imperative) with recommended standards and comparison between the output of Compact Fluorescent Lamps (CFL) and the LEDs. Walk-through Energy audit approach was used to evaluate the percentage lightning occupies which involves identification and grouping of all electrical loads with their respective power rating in Watts. Similarly, illumination level verification campaign was conducted with the use of a digital light meter (sensor based device) connected to a Personal Computer for logging illumination level real time along the aisles and reading cubicles. The same light meter was used for comparing the output of installed CFL and proposed LED. Results indicate that lighting fixtures occupy $12.2 \%$ of the load spectrum. The lighting installations also do not conform to global illumination standards for the facility accessed while the output of the LED tested is still low. It is therefore recommended that better LED light sources be considered for efficient energy, reduction in environmental pollution associated with power generation, reduction in power needed to maintain a cooling effect and cost economy.
\end{abstract}

Keywords: CFL, LEDs, lumens, illumination level verification, power sector, environmental pollution.

\section{BACKGROUND}

Energy consumption worldwide is growing as advancements in technology continue to deliver alternative and efficient systems that serve basic human needs for heating, cooling, ventilation, air conditioning, lighting, etc. Study has shown that lighting fixtures account for about $19 \%$ of electricity consumption worldwide (Deswert et al., 2009). Renewable and efficient energy has been recommended in recent times as a sustainable concept for managing the dwindling resources in the energy sector, reducing ozone layer depletion and reducing the cost of energy (Froechlich et al., 2011).

The motivation for an efficient lighting system is drawn from the deployment of renewable energy systems and proper metering of homes in Nigeria. People are now more conscious of the rating of their appliances, its corresponding effect on the energy consumption and the cumulative effect on the environment. Although there are notable innovations in the lighting technology and had grown consistently over the years, performance however depends on a number of other factors.

The deployment of recent technologies such as the Compact Fluorescent Lamps (CFL) has reduced the energy consumed by lighting systems but technological advances in Light Emitting Diodes (LED) are becoming more convincing in their power consumption and lumens output. The demand for the latter is on the increase in Nigeria and its implementation can enhance a more efficient utilization of available energy.

Other common type of lighting fixtures include the fluorescent straight tube, incandescent tungsten halogen. The breakdown of the power consumption and lumens delivered by each of these lighting fixtures is shown in Figure 1. It summarizes the watt per lumen consumption of the different light sources. 


\section{Energy use by Indoor Lighting Type (range) \\ Data from U.S. Department of Energy}

\section{LED, warm white}

LED, cool white

Fluorescent, circline

Fluorescent, compact [CFL]

Fluorescent, straight tube

Incandescent, tungsten halogen

Incandescent, tungsten [most common]

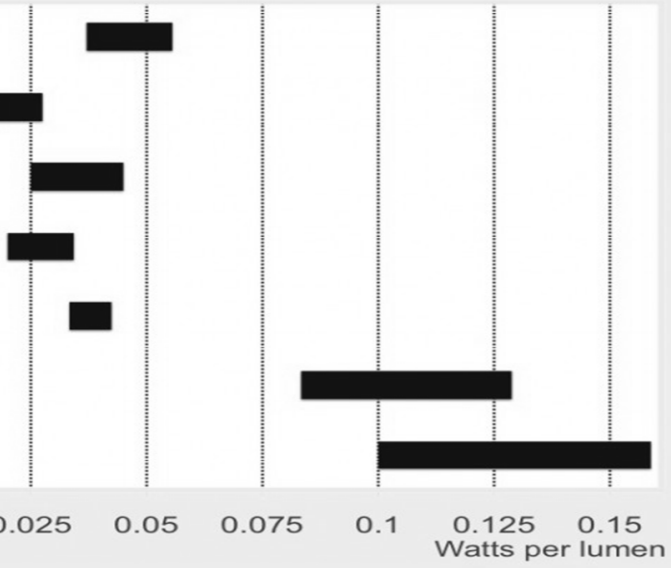

Figure 1. Comparison between different light sources in terms of watts per lumen ("Energy Efficiency ", 2012).

John Mulholland (2003), highlighted the benefits of an effective lighting system. He opined that such a system saves energy and running costs, improves productivity of end user, reduces maintenance costs, improves security and safety, enhances visual environment, and provides end users with local control. Interestingly, the lighting fixtures at the main campus of Osun State University is dominated by the CFL and LED. Moreover, the incessant supply of power to this academic community and its environs has attracted a great deal of attention from various research groups for sustainable renewable energy solutions.

This study is therefore aimed at evaluating the performance of the lighting fixtures in use at the main campus of Osun State University, i.e. the CFL and LED, while also presenting estimates of the energy consumption/demand as required for sustainable eco-friendly solutions for this community.

\section{RELATED WORK}

In Nigeria, the major lighting fixtures in use are incandescent bulbs, halogen lamps, fluorescent tubes and compact fluorescent lamps (CFLs). A previous research shows that incandescent bulbs are the most utilized lighting unit in Nigeria, occupying about $65 \%$ of the total lighting loads. The research further identified that majority of the power consumed by incandescent bulbs is given off in form of heat and only about $5 \%$ is converted light energy (Etiosa Uyigue, 2009). In a more recent study in Calabar (a prominent city in the SouthSouthern part of Nigeria), $24 \%$ of the total respondents use CFLs, while $60 \%$ of the respondents use incandescent bulbs. Only $16 \%$ of the respondents use both the CFLs and Incandescent Bulbs (Obafemi \& Ifere, 2013).

Veitch \& Newsham (1998) tested the hypothesis that lighting quality, affects the task performance, mood, comfort, health, and aesthetic judgements of office workers. The results show that energy-efficient lighting and good-quality lighting can be compatible. (Veitch \& Newsham, 1998). A similar experiment was carried out in the work of Dianat, Sedghi, Bagherzade, Jafarabadi, and Stedmon (2013), to evaluate the illumination levels, to examine the effect of lighting conditions on employee satisfaction, job performance, safety and health, and to compare the employees' perception of lighting level with actual illuminance levels in a hospital setting using both questionnaire and physical illuminance measurements. The findings suggest that environmental ergonomics should be given a more prominent role in hospital building and workplace design to support safer healthcare facilities.

In a similar study, Sperber, Elmore, Crow, and Cawlfield (2012) focused on characterizing the potential benefits associated with using energy efficient exterior area lighting commonly associated with remote installations. A comparison with lighting standards for specific purposes such as security lighting indicates that LEDs may be appropriate for applications where a metal halide system would provide significantly more illumination than required at a much higher energy cost. In (Li \& Lam, 2001), field measurements on daylighting for a fully air-conditioned office building in Hong Kong was conducted, where the electricity consumption by the fluorescent luminaires, indoor illuminance levels and the room parameters affecting daylighting designs were recorded and analysed. The findings suggest that daylighting schemes can result in substantial energy savings in air-conditioned office buildings.

A detailed comparative analysis between domestic lighting lamps (DLLs) which includes incandescent lamp (IL), fluorescent lamp (FL), compact fluorescent lamp (CFL) and Light Emitting Diodes (LED) was conducted in (Aman, Jasmon, Mokhlis, \& Bakar, 2013). The result shows that with the current technology, the 
use of FL and LED lamp is beneficial for utility as well as for consumer.

Several tests were also conducted by Coca, Popa, and Buta (2011) on different types of CFL, from different manufacturers, in order to determine the level of electromagnetic pollution. Results were compared against the limits provided by the International Special Committee on Radio Interference, CISPR 22 international standard. A similar study (Ivanovici, Popa, Golovanov, \& Țipu, 2013) was carried out on the performance of CFLs with improved technical characteristics as compared to the products existing earlier.

The main objective of this study is to evaluate the performance of the prominent and recent lighting fixtures (CFL and LED) based on acceptable standards, using installations at the old library building on the main campus of Osun State University. The audit of energy for buildings at Osun State University, Osogbo, is also considered necessary for facilitating the current drive for renewable solutions, which will invariably reduce the dependence on generator and also eliminate associated environmental pollution.

\section{METHODOLOGY}

In achieving the objectives of this research, energy audit exercise was carried out and the performance of the lighting fixtures was also evaluated.

\section{Energy audit}

According to Corzine and Jackson (2006), an energy audit identifies where energy is consumed and how much energy is consumed in an existing facility, building or structure. Apart from the provision of realistic estimates for planning and designing renewable energy solutions, this audit also gives room for the assessment of the percentage that lighting loads actually occupy in the total load spectrum in the selected buildings.

The two buildings were selected as case studies and they are the Senate/Administrative building and College of SET building, both situated on the main campus of Osun State University in Osogbo, the State Capital of the State of Osun. These two buildings were selected because they are similar structures, with duplication on the other five (5) campuses of the University. Hence, result obtained from these buildings can be used as a benchmark for making decision on those similar structures. The following steps were followed in carrying out the energy audit

(i) Initial on-site inspection (ii) Data gathering and assessment and (iii) Data analysis and evaluation

\section{Initial on-site Inspection}

An initial inspection of building components and equipment was carried out in order to determine the appropriate approach to be adopted. This study adopted the "walk-through" approach to energy auditing which involves a visual inspection of the facilities and associated systems in the building. The walk-through approach was favored over the standard audit approach because of the absence of sectionalized meters in the buildings.

The buildings consist of the following sections and their respective electrical gadgets: private and general offices, reception rooms, lecture rooms and theatres, laboratories, meeting halls, stores, restrooms, walkways and staircases.

\section{Data Gathering and Assessment}

This step involves the physical inspection of the facilities installed in the buildings but this time with the purpose of identifying 'which' and 'how many' electrical gadgets are available in every section of the building. Alongside this, their corresponding power rating (wattage) and average duration of usage per day (in hours) were also assessed by interrogating the users of such devices. The wattage for the equipment can be gotten on its name plate or verified at the manufacturer's website through equipment's name and series number.

\section{Data Analysis and Evaluation}

In analyzing the data collected, similar loads were grouped together under the following headings: Cooling units, Office Equipment, Entertainment systems, Lighting fixtures, Communication devices, Security fixtures and miscellaneous equipment. The details of this grouping are shown in Table 1. The lighting fixtures mainly comprise of compact fluorescent lamps (as office and security lamps) with few fluorescent lamps (as office lamps) and some LED based halogen lamps (as security lamps).. 
Table 1: Equipment grouping for the energy audit exercise

\begin{tabular}{|c|c|c|c|c|c|}
\hline \multicolumn{2}{|c|}{ A. COOLING UNITS } & \multicolumn{2}{|r|}{$\begin{array}{ll}\text { B. } & \text { OFFICE } \\
& \text { EQUIPMENT }\end{array}$} & \multicolumn{2}{|r|}{$\begin{array}{ll}\text { C. } & \text { MISCELLANEOUS } \\
\text { EQUIPMENT }\end{array}$} \\
\hline 1 & Air conditioning Units & 1 & Computer(CPU) & 1 & Microwave oven \\
\hline 2 & Fans & 2 & $\begin{array}{l}\text { Computer } \\
\text { (Monitor) }\end{array}$ & 2 & Electric Jug \\
\hline 3 & Refrigerators & 3 & Laptops & 3 & Other sockets loads \\
\hline \multicolumn{2}{|r|}{ D. ENTERTAINMENT SYSTEMS } & 4 & Printers & 4 & Pumping Machines \\
\hline 1 & Television & 5 & Photocopiers & 5 & Laboratory Experiments \\
\hline 2 & Stereo Component & 6 & Scanners & 6 & Vacuum Cleaner \\
\hline 3 & DSTV Decoder & 7 & Projector & 7 & Water Dispenser \\
\hline 4 & DVD Player & 8 & ID Card Printer & \multicolumn{2}{|c|}{ G. SECURITY FIXTURES } \\
\hline 5 & Star times $\AA$ decoder & 9 & HP Plotters & 1 & CCTV Cameras \\
\hline & & 10 & Digital Counter & 2 & DVR \\
\hline & & 11 & Pay-roll Printer & 3 & Security Door \\
\hline & & \multicolumn{4}{|c|}{ COMMUNICATION DEVICES } \\
\hline & E. LIGHTING FIXTURES & 1 & Mobile Phones & 5 & Public Address System \\
\hline 1 & Office Lamps & 2 & $\begin{array}{l}\text { Other } \\
\text { communication } \\
\text { devices }\end{array}$ & 6 & Linksys Switch \\
\hline 2 & Security and other Lamps & 3 & $\begin{array}{l}\text { Central Inter- } \\
\text { comm. Device }\end{array}$ & 7 & Cnet ${ }^{\circledR}$ Switch \\
\hline 3 & Rechargeable lamps & 4 & Walkie-Talkies & & \\
\hline
\end{tabular}

\section{Evaluation of the Performance of the Lighting Fixtures}

An experimental campaign was conducted with the use of digital light meters, which is a sensor based equipment connected to a personal computer for logging illumination level real time. The performance of the CFLs was evaluated using the installations in reading rooms at the Library Facility. The University library reading rooms were selected since it is a critical visual environment with a high volume of traffic. This traffic is build up by students and staff and this facility is open between 8 am and $6 \mathrm{pm}$ during weekdays. The two reading rooms are similar as shown in Figure, which shows the plan view of the library reading rooms. ' $\mathrm{T}$ ' and ' $\mathrm{a}$ ' represents 'reading tables' and 'aisles' respectively. The measurements were carried out at the points marked ' $\mathrm{X}$ ' along the aisles as shown in the Figure, making a total of 60 measurement points in each reading room. The lighting points are marked yellow in the same Figure.

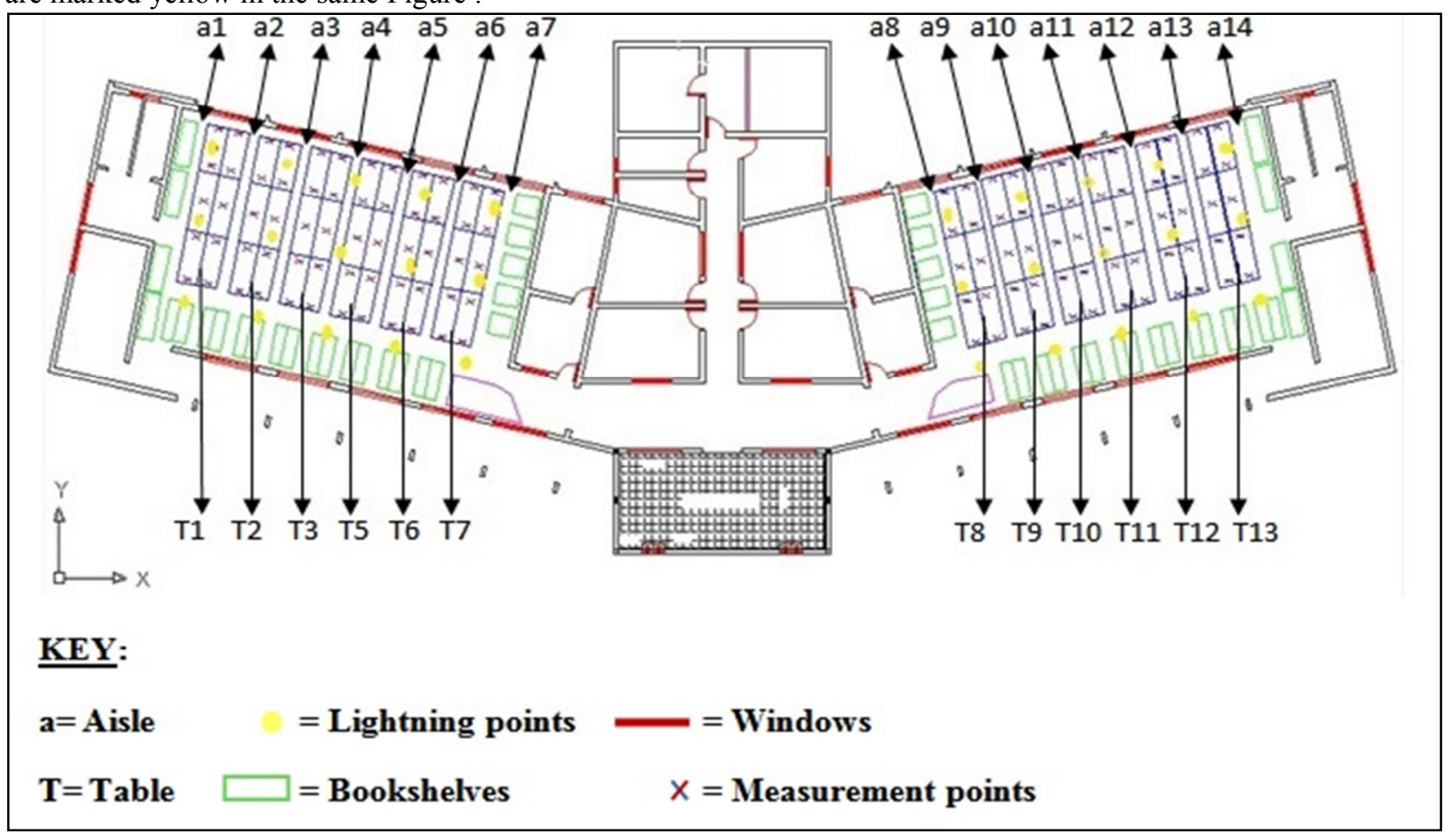

Figure 2: Plan view of measurement location for performance evaluation. 
The measurement setup is made up of an Extech Heavy Duty Light Meter (model 407026) and a personal computer for logging the data. The setup is as shown in Figure 3.

In determining the minimum number of measurement points for the room, it is necessary to determine the room index using Equation 1.

$$
\text { Room Index }(\mathrm{k})=\frac{\text { Lenght } * \text { Width }}{H *(\text { Lenght }+ \text { Width })}
$$

where $H$ represents the height of the luminaries above the plane of measurement. ("Exercise on Lighting Survey and Assessment," 2002). The software used for data logging is the Extech Data Acquisition Software, which is compatible with the Extech Heavy Duty Light Meter shown in Figure 3.

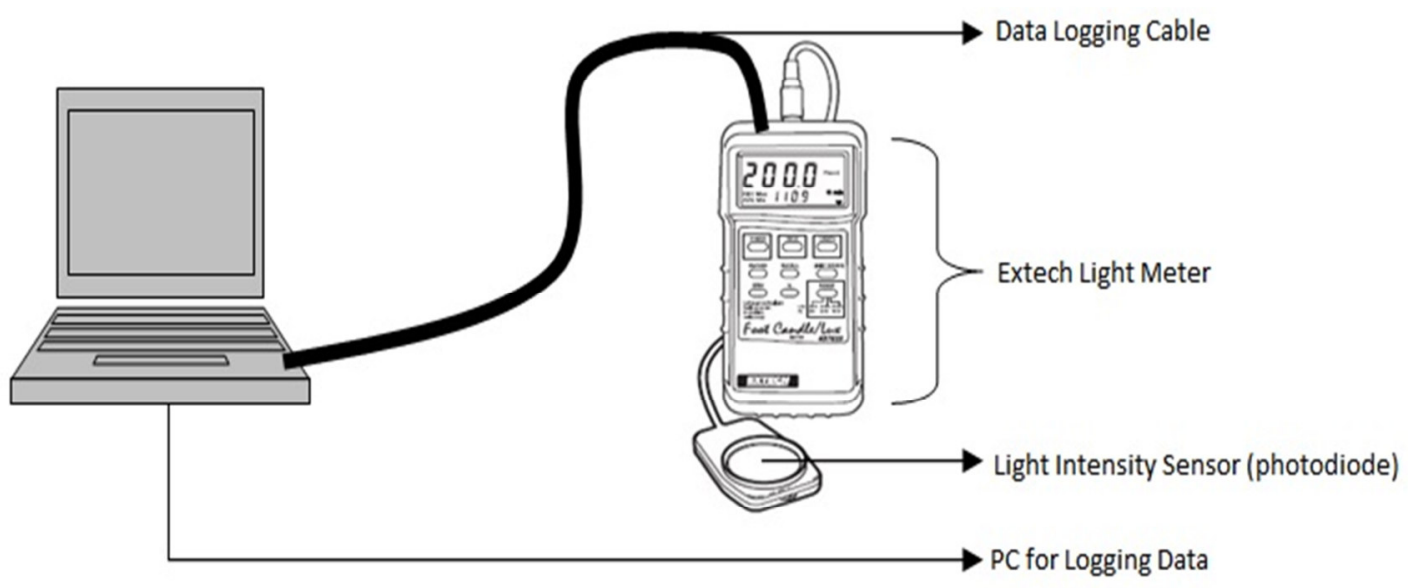

Figure 3. Measurement set up for illumination level verification.

An office in the College of SET was used for evaluating the performance of the LED fixture using the setup shown in Figure 3., the illumination levels for the three different lighting systems shown in Figure 4, Figure and Figure 6 (which are CFL based, Single LED and Doubled LED systems respectively) were measured.

The measurements were taken at the table level $(0.76 \mathrm{~m}$ from floor level) across the office starting from point ' $\mathrm{A}$ ' following the dashed line shown to the center of the office at point ' $\mathrm{B}$ ' in order to have a uniform representation of the illumination level across the office. The total distance along the dashed line from end ' $A$ ' to end ' $\mathrm{B}$ ' is $33.4 \mathrm{~m}$ while the total height, length and breadth of the office are $3.4 \mathrm{~m}, 3.7 \mathrm{~m}$ and $3.58 \mathrm{~m}$ respectively.

The specifications for CFL and LEDs used in this project are detailed in Table 2.2.

Table 2. Specification for the lighting fixtures tested.

\begin{tabular}{|l|l|l|l|}
\hline S/N & PROPERTY & CFL & LED FIXTURE \\
\hline $\mathbf{1}$ & Colour & White & White \\
\hline $\mathbf{2}$ & AC Input Voltage & $220-240 \mathrm{~V}$ & $85-265 \mathrm{~V}$ \\
\hline $\mathbf{3}$ & Operating frequency & $(50 / 60) \mathrm{Hz}$ & $(50 / 60) \mathrm{Hz}$ \\
\hline $\mathbf{4}$ & Wattage & $85 \mathrm{~W}$ & $12 \mathrm{~W}$ \\
\hline $\mathbf{5}$ & Average Life & $6,000-8,000 \mathrm{hrs}$ & $50,000 \mathrm{hrs}$ \\
\hline $\mathbf{6}$ & Beam angle & $360^{\circ}$ & $120^{\circ}$ \\
\hline $\mathbf{7}$ & Lumen & $>20001 \mathrm{~m}$ & $400-12001 \mathrm{~lm}$ \\
\hline
\end{tabular}




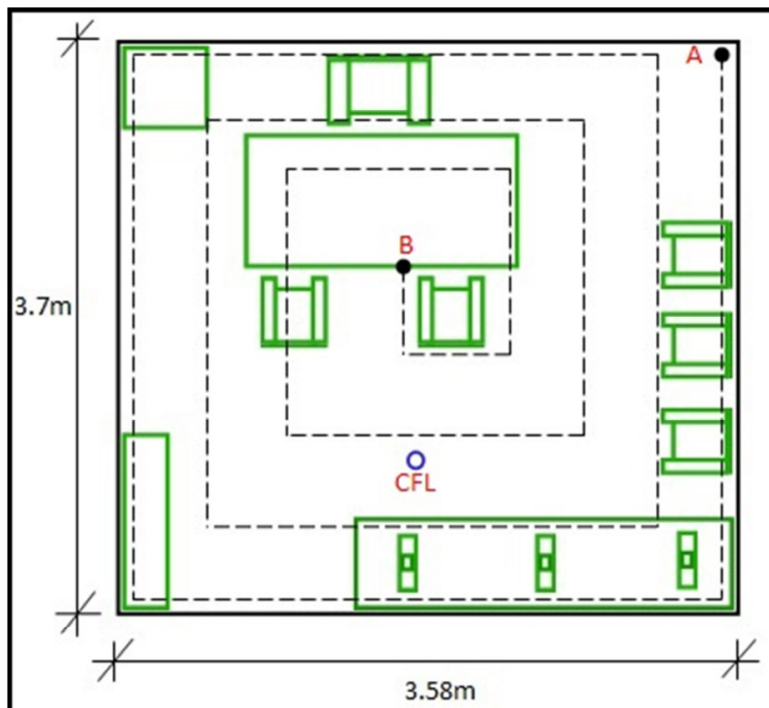

Figure 4. Arial view of office showing location of CFL and measurement points

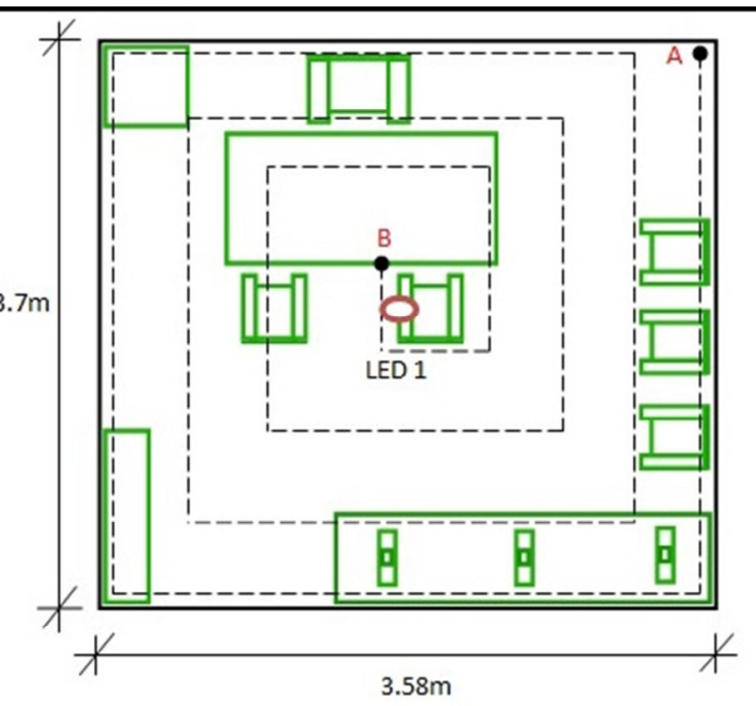

Figure 5. Arial view of office showing location of Single LED and measurement points

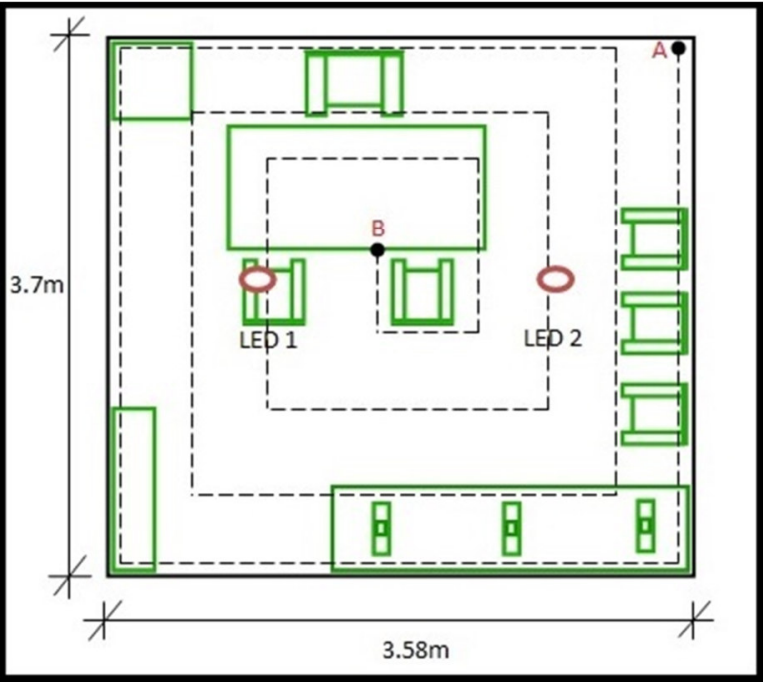

Figure 6. Arial view of office showing location of two LEDs and measurement points

\section{RESULTS AND DISCUSSION}

The results obtained during the energy audit at the Administrative and College of SET buildings, illumination level verification at the University Library's reading rooms and comparison of light output for the CFL in use and the LED fixtures are presented in this section.

The results obtained from the Energy audit for Administrative and College of SET buildings are summarized in Table 2 and Table 3 . The "Peak Daily Requirement" column shows the power requirement on a typical office day while the "Peak Yearly Requirement" column shows yearly power requirement, taking into consideration reduced power consumption on weekends and public holidays. Table 2 presents a summary of the power requirement for the Administrative Building with an estimated daily consumption of 2,165.45 KWH, and $552,469.14 \mathrm{KWH}$ as the peak yearly consumption. Table 3 provides a similar estimate for the SET Building where the peak daily consumption totals $2,329.84 \mathrm{KWH}$, while the yearly consumption totals $591,326.81 \mathrm{KWH}$. The two tables show that lighting occupies $15.3 \%$ and $13.7 \%$ of the estimated yearly power consumption for Administrative and College of SET respectively. However, it should be noted that these figures were estimated, the real power consumption is expected to vary slightly from these values as a result of seasonal variations in power consumption. 
Table 2: Summary of Energy Audit for Administrative Building.

\begin{tabular}{|c|l|c|c|c|c|}
\hline S/N & EQUIPMENT & $\begin{array}{c}\text { ESTIMATED } \\
\text { PEAK DAILY } \\
\text { CONSUMPTION } \\
\text { (KWH) }\end{array}$ & $\begin{array}{c}\text { ESTIMATED } \\
\text { PEAK DAILY } \\
\text { POWER } \\
\text { REQUIREMENT } \\
\text { (KW) }\end{array}$ & $\begin{array}{c}\text { ESTIMATED } \\
\text { PEAK YEARLY } \\
\text { CONSUMPTION } \\
\text { (KWH) }\end{array}$ & PERCENTAGE \\
\hline $\mathbf{1}$ & $\begin{array}{l}\text { Cooling } \\
\text { Equipment }\end{array}$ & $1,031.77$ & 127.092 & $255,879.55$ & $46.30 \%$ \\
\hline $\mathbf{2}$ & $\begin{array}{l}\text { Entertainment } \\
\text { Systems }\end{array}$ & 30.60 & 4.549 & $7,588.43$ & $1.40 \%$ \\
\hline $\mathbf{3}$ & $\begin{array}{l}\text { Lighting } \\
\text { Fixtures }\end{array}$ & 277.44 & 29.894 & $84,241.56$ & $15.30 \%$ \\
\hline $\mathbf{4}$ & $\begin{array}{l}\text { Office } \\
\text { Equipment }\end{array}$ & 622.29 & 111.949 & $154,328.77$ & $27.90 \%$ \\
\hline $\mathbf{5}$ & $\begin{array}{l}\text { Communication } \\
\text { Devices }\end{array}$ & 156.63 & 7.156 & $38,843.94$ & $7.00 \%$ \\
\hline $\mathbf{6}$ & $\begin{array}{l}\text { Security } \\
\text { Fixtures }\end{array}$ & 6.78 & 0.695 & $1,681.44$ & $0.30 \%$ \\
\hline $\mathbf{7}$ & Miscellaneous & 39.94 & 9.315 & $9,905.46$ & $1.80 \%$ \\
\hline & & $\mathbf{2 , 1 6 5 . 4 5}$ & $\mathbf{2 9 0 . 6 5 0}$ & $\mathbf{5 5 2 , 4 6 9 . 1 4}$ & $\mathbf{1 0 0 . 0 0 \%}$ \\
\hline
\end{tabular}

Table 3: Summary of Energy Audit for College of SET Building.

\begin{tabular}{|c|c|c|c|c|c|}
\hline $\begin{array}{l}\mathbf{S} \\
/ \\
\mathbf{N}\end{array}$ & EQUIPMENT & $\begin{array}{l}\text { ESTIMATED } \\
\text { PEAK DAILY } \\
\text { CONSUMPTION } \\
\text { (KWH) }\end{array}$ & $\begin{array}{c}\text { ESTIMATED } \\
\text { PEAK DAILY } \\
\text { POWER } \\
\text { REQUIREMENT } \\
(\text { KW) } \\
\end{array}$ & $\begin{array}{c}\text { ESTIMATED } \\
\text { PEAK YEARLY } \\
\text { CONSUMPTION } \\
\text { (KWH) }\end{array}$ & PERCENTAGE \\
\hline 1 & $\begin{array}{l}\text { Cooling } \\
\text { Equipment } \\
\end{array}$ & 926.10 & 115.265 & $229,673.61$ & $38.80 \%$ \\
\hline 2 & $\begin{array}{l}\text { Entertainment } \\
\text { Systems }\end{array}$ & 13.72 & 1.986 & $3,403.30$ & $0.60 \%$ \\
\hline 3 & $\begin{array}{l}\text { Lighting } \\
\text { Fixtures }\end{array}$ & 271.98 & 26.885 & $80,978.58$ & $13.70 \%$ \\
\hline 4 & $\begin{array}{l}\text { Office } \\
\text { Equipment }\end{array}$ & 755.35 & 131.870 & $187,327.42$ & $31.70 \%$ \\
\hline 5 & $\begin{array}{l}\text { Communication } \\
\text { Devices }\end{array}$ & 30.52 & 4.047 & $7,568.71$ & $1.20 \%$ \\
\hline 6 & $\begin{array}{l}\text { Miscellaneous } \\
\text { Equipment }\end{array}$ & 332.16 & 49.867 & $82,375.18$ & $14.00 \%$ \\
\hline & Total & $2,329.84$ & 329.920 & $591,326.81$ & $100.00 \%$ \\
\hline
\end{tabular}




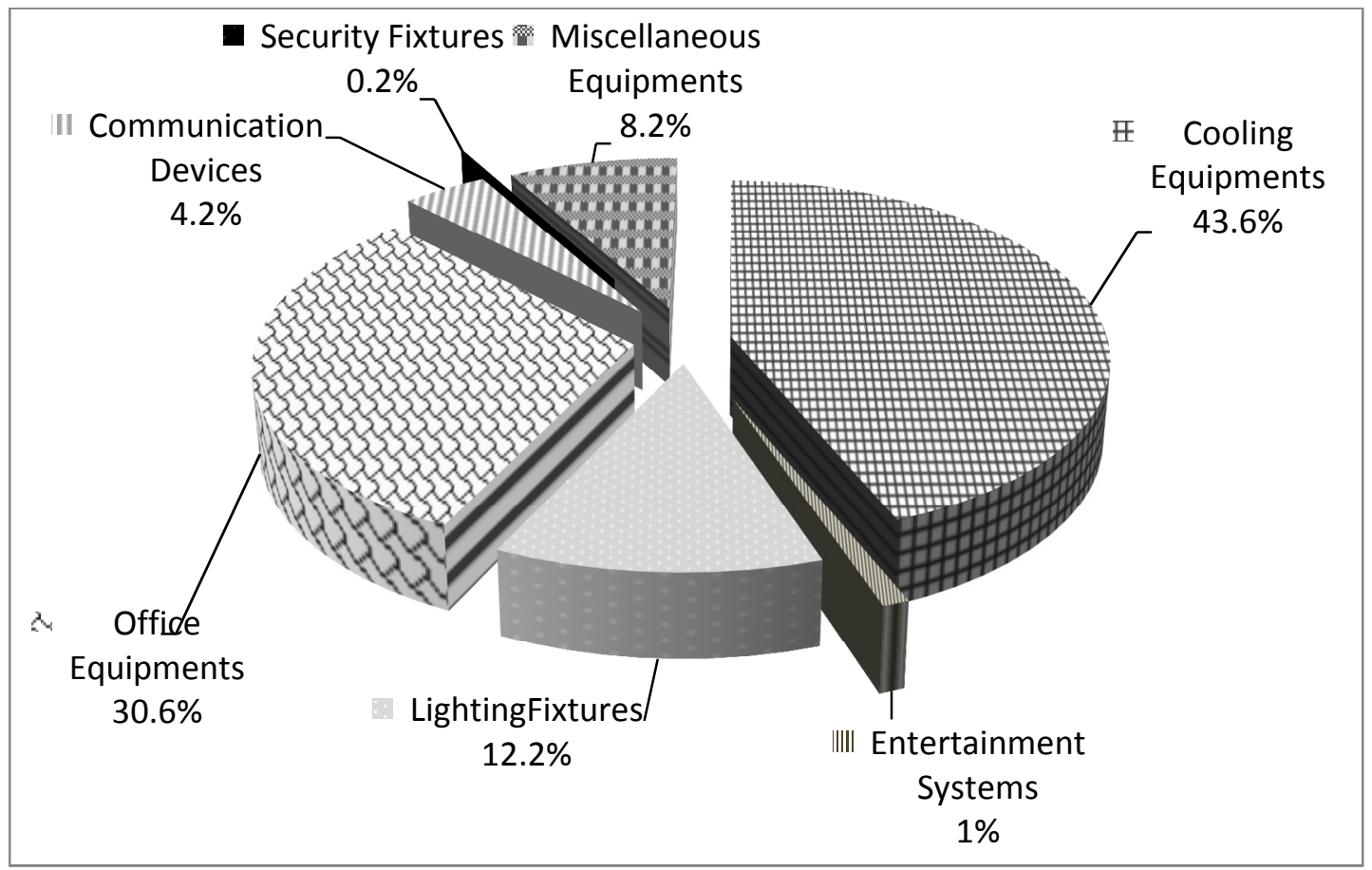

Figure 7. Cumulative summary of the Percentage distribution of the total daily power requirement for the two buildings.

The cumulative summary of the daily power requirement for the two buildings is presented in Figure 7. It shows that cooling equipment occupying the highest percentage (46.3\%), lightning occupies only $12.2 \%$ and security fixtures occupying just $0.2 \%$. The $12.2 \%$ occupied by LED is evidently as a result of the use of energy saving CFLs.

The result for the measurement taken at the Library is as shown in Figure 8. As shown in Figure 2, there are six (6) rows of tables in each of the reading rooms. One end of the tables was arranged beside the windows along the northern wall which had an effect on the measurements taken because of ambient light from the sun since the measurements were taken during the day. The six peaks shown in Figure 8 represents readings taken at these ends. It can be observed that these peaks are not uniform which is clearly as a result of the arrangement of the different ends of the tables. They are not centralized uniformly beside the windows.

As observed from the results obtained, the illumination level at most of the measurement points are actually below the $300 \mathrm{~lm}$ (although the readings were taken at the table level) which is the recommended standard stated for prolonged reading periods (IES, 1999). Table 4 presents the summary of the readings recorded. The lowest readings $(10 \mathrm{~lm})$ was recorded in reading room $\mathrm{B}$.

The result obtained from the comparison between LED and CFL light sources is shown in Figure 9. The results for the single LED light source falls below the lower limit specified in IESNA standard for most of the sections covered. The result obtained for two LED light sources is similar to that obtained when using a single CFL light source.

Table 4: Summary of results obtained from the measurment taken in the University Library.

\begin{tabular}{|c|c|c|c|c|}
\hline S/N & LOCATION & $\begin{array}{c}\text { MAXIMUM READING } \\
\text { (lumens) }\end{array}$ & $\begin{array}{c}\text { MINIMUM READING } \\
\text { (lumens) }\end{array}$ & $\begin{array}{c}\text { AVERAGE } \\
\text { READING (lumens) }\end{array}$ \\
\hline 1 & Reading room A & 651 & 35 & 135 \\
\hline 2 & Reading room B & 615 & 10 & 167 \\
\hline
\end{tabular}

Table 5: Summary for light level comparison between CFL and LED.

\begin{tabular}{|l|l|c|c|c|}
\hline S/N & EQUIPMENT & $\begin{array}{l}\text { MAXIMUM READING } \\
\text { (lumens) }\end{array}$ & $\begin{array}{l}\text { MINIMUM READING } \\
\text { (lumens) }\end{array}$ & $\begin{array}{l}\text { AVERAGE READING } \\
\text { (lumens) }\end{array}$ \\
\hline 1 & Single CFL & 104 & 34 & 76 \\
\hline 2 & Single LED & 55 & 15 & 31 \\
\hline 3 & Double LED & 85 & 36 & 62 \\
\hline
\end{tabular}




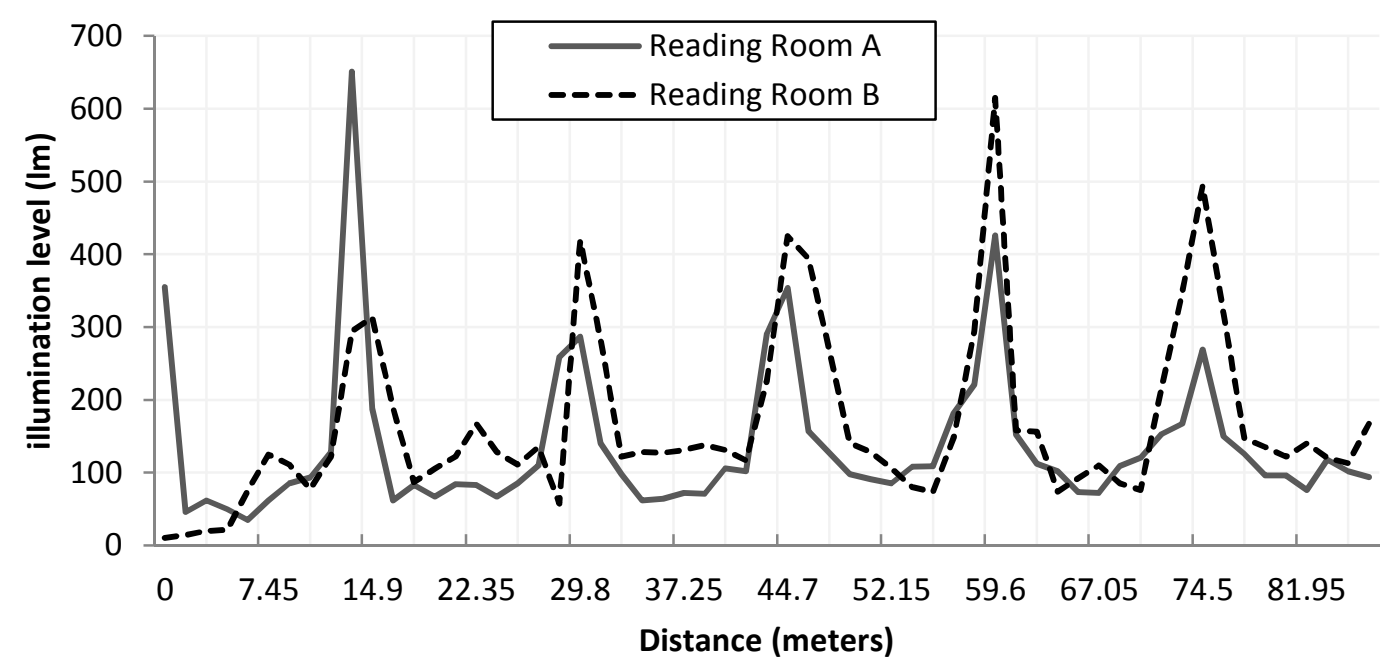

Figure 8. Result for illumination level in the two reading rooms at the University Library

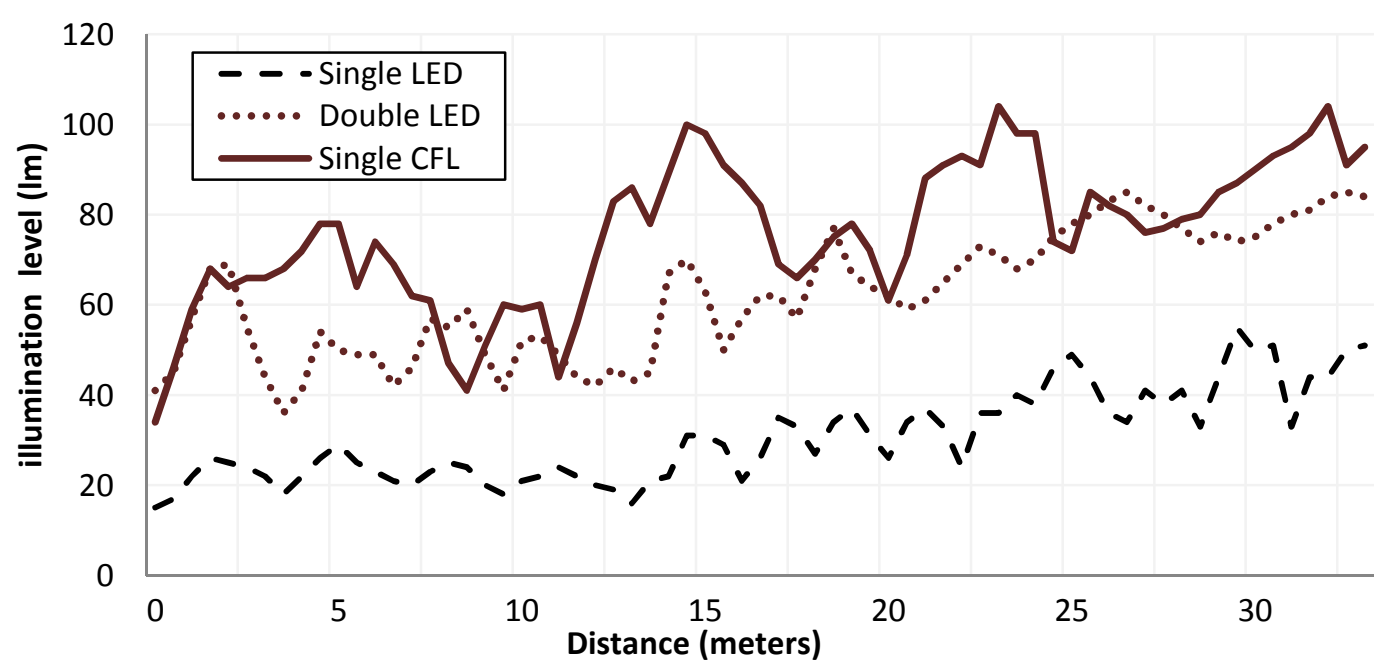

Figure 9: Result for illumination level comparison between single CFL with Single and Double LED

The lowest readings are recorded around the walls as evident if a straight line drawn to join the two ends of the plots will have a positive gradient for the three different results in Figure 9 (CFL, single LED and double LED measurements). This means that the light level increases from end A to end B for the two LEDs. The horizontal axis represents the distance along measurement points with a total length of $33.4 \mathrm{~m}$ while the illumination level was plotted on the vertical axis.

It can also be observed that the output for this LED fixture used is lower than that of the CFL. This is similar to the result obtained by (Matei). The maximum, minimum and average readings recorded is summarized in Table 5. The average reading across the room for single LED light source is $31 \mathrm{~lm}$ which is a relatively low value when compared with the average the $62 \mathrm{~lm}$ value recorded for double LED, and quite close to the average reading for single CFL.

\section{CONCLUSION}

The performance of selected illumination sources have been assessed experimentally on selected facilities in Osun State University, Osogbo. The percentage energy consumption by existing lighting fixtures was quantified through an energy audit exercise on two main buildings - the Administrative building and College of Science, Engineering and Technology building. The lighting fixtures occupy only $12 \%$ of the total load spectrum for the two buildings. Although the adoption of the CFL based illumination units offers a substantial reduction in energy consumption as compared to the initial Incandescent bulbs and the straight tube fluorescent lamps illumination systems, it is apparent that more savings can be incurred with the deployment of appropriate LED based lighting fixtures. However, as observed from the results from the single and double LED installations, the electrical design for the installation of the lighting source actually plays a significant role in achieving an optimal 
performance. The lighting installations do not conform to global illumination standards for the facilities assessed. The use of LEDs will lead to heat emission control in the confined office, library, classroom and laboratory spaces, thereby reducing the power utilised in maintaining a certain temperature for cooling. Adopting the use of LED for lighting fixtures will invariably cause reduction in energy consumption, and is also considered most suitable for the conserving energy, especially from the renewable solutions.

\section{REFERENCES}

Figure 1, "Lighting" (2012). BURN An Energy Journal, available at http://burnanenergyjournal.com/energyefficiency-2/

Aman, M. M., Jasmon, G. B., Mokhlis, H., \& Bakar, A. H. A. (2013). Analysis of the performance of domestic lighting lamps. Energy Policy, 52, 482-500. doi:https://doi.org/10.1016/j.enpol.2012.09.068

Coca, E., Popa, V., \& Buta, G. (2011, 27-29 April 2011). Compact fluorescent lamps electromagnetic compatibility measurements and performance evaluation. Paper presented at the 2011 IEEE EUROCON International Conference on Computer as a Tool.

Corzine, J. S., \& Jackson, L. P. (2006). How to Conduct an Energy Audit: A Short Guide for Local Governments and Communities. Trenton, New Retrieved from www.state.nj.us/dep/dsr/bscit/SustCommunities.htm.

Deswert, J.-M., Dussaigne, A., Eugen, C., Fontoynont, M., Gasse, A., Gilet, P., . . Zissis, G. (2009). LEDs for Lighting Applications. In P. Mottier (Ed.), LEDs for Lighting Applications. London SW19 4EU and Hoboken, NJ 07030: ISTE Ltd and John Wiley \& Sons, Inc.

Dianat, I., Sedghi, A., Bagherzade, J., Jafarabadi, M. A., \& Stedmon, A. W. (2013). Objective and subjective assessments of lighting in a hospital setting: implications for health, safety and performance. Ergonomics, 56(10), 1535-1545. doi:10.1080/00140139.2013.820845

Energy Efficiency (2012). from Soundvision Productions http://burnanenergyjournal.com/energy-efficiency-2/

Etiosa Uyigue, M. A., Agharese Edevbaro, Ogbemudia Osamuyi Godfrey, Osazee Paul Uyigue, Ose Golden Okungbowa. (2009). Energy Efficiency Survey in Nigeria. Retrieved from Edo State, Nigeria: www.credcentre.org

Exercise on Lighting Survey and Assessment. (2002). Retrieved 10/10/2014 http://www.hku.hk/bse/bbse2002/index.html

Froechlich, J., Larson, E., Gupta, S., Cohn, G., Reynolds, M. S., \& Patel, S. N. (2011). Disaggregated End-Use Energy Sensing for the Smart Grid. IEEE Pervasive Computing, Special Issue on Smart Energy Systems,(Jan-Mar 2011 issue).

Haitz, R., Kish, F., Tsao, J., \& Nelson, J. (2002). Another semiconductor revolution: this time it's lighting. Compound Semiconductor Magazine.

IES. Room Illumination Level.

Ivanovici, C., Popa, I., Golovanov, N., \& Țipu, E. (2013, 23-25 May 2013). Performance evaluation of some compact fluorescent lamps equipped with electronic ballasts based on specialized integrated circuits. Paper presented at the 2013 8TH INTERNATIONAL SYMPOSIUM ON ADVANCED TOPICS IN ELECTRICAL ENGINEERING (ATEE).

John Mulholland, D. S. H., Chris Roberts (2003). Energy Management in Buildings. PRACTITIONER, Volume 4, 38. Retrieved from

Li, D. H. W., \& Lam, J. C. (2001). Evaluation of lighting performance in office buildings with daylighting controls. Energy and Buildings, 33(8), 793-803. doi:https://doi.org/10.1016/S0378-7788(01)00067-6

Matei, S. Efficient Household Lighting: A Model of Solid-State with LED Illumination. Cape Peninsula University of Technology, Cape Town South Africa.

Obafemi, F. N., \& Ifere, E. O. (2013). Non-Technical Losses, Energy Efficiency and Conservative Methodology in the Electricity Sector of Nigeria: The Case of Calabar, Cross River State. International Journal of Energy Economics and Policy, Volume 3(No. 2), 185-192.

Sperber, A. N., Elmore, A. C., Crow, M. L., \& Cawlfield, J. D. (2012). Performance evaluation of energy efficient lighting associated with renewable energy applications. Renewable Energy, 44, 423-430. doi:https://doi.org/10.1016/j.renene.2012.01.001

Veitch, J. A., \& Newsham, G. R. (1998). Lighting Quality and Energy-Efficiency Effects on Task Performance, Mood, Health, Satisfaction, and Comfort. Journal of the Illuminating Engineering Society, 27(1), 107-129. doi:10.1080/00994480.1998.10748216 